\title{
Authors' reply: Comment on: Empathy and burnout: a study on residents from a Singapore INSTITUTION
}

Singapore Med J 2018; 59(3): 168 https://doi.org/10.11622/smedj.2018034

Dear Sir,

We thank the authors for their interest in our paper and the thoughtful comments. ${ }^{(1)}$ Burnout comprises three interrelated dimensions: emotional exhaustion (EE), depersonalisation (DP) and low personal accomplishment (PA). ${ }^{(2)}$ The Maslach Burnout Inventory (MBI) is the most frequently used questionnaire and includes 22 items that measure all three burnout dimensions (seven-item EE subscale, eight-item PA subscale and seven-item DP subscale). Although several studies focus on the presence of high levels of EE or DP alone, other burnout studies have also included all three components in their measurement of burnout. ${ }^{(3,4)}$ Furthermore, even if burnout prevalence is defined as high EE or DP in our study instead of the current definition of high EE, high DP or low PA, the difference is small (354/446, 79.4\% vs. 360/446, 80.7\%, respectively) and does not change the conclusion of our paper.

At the time of writing, our study was the first in Singapore to evaluate empathy and burnout among residents. ${ }^{(5)}$ We acknowledge that burnout studies have been performed in other medical cohorts, such as nurses and medical students. The other local burnout study by See et al, ${ }^{(6)}$ which involved 64 trainees, was published in October 2016 and our manuscript was submitted prior to that.

While there are 34 different residency programmes in our institution, numbers of residents within each programme vary greatly, from as low as one (hand surgery) to as high as 153 (internal medicine). Without grouping similar programmes together, a meaningful comparison would not have been possible and may have revealed the identity of the programmes and participants.

The Jefferson Scale of Physician Empathy for students (JSPE-S) and JSPE for physicians and health professionals are similar in content, differing only in the wording of the questions, which address the population they are targeted at. The website for the Jefferson Center for Research in Medical Education and Health Care states, "Both are similar in content with minor modifications in wording to avoid confusion. For example, an item beginning 'Physicians' understanding...' in the medical student version may begin 'Health care providers' understanding...' in the health professions student version" ${ }^{\prime(7)}$ Testing for internal consistency in our sample revealed a Cronbach's alpha of 0.87 , which indicates good internal consistency and is indeed similar to what some of our authors have previously reported for the JSPE-S (0.83). ${ }^{(8)}$

The statement that "Medical students in Singapore have been shown to be less empathetic than their counterparts from the US, although they were relatively more empathetic compared to counterparts from East Asia" is also attributable to the same cited paper. ${ }^{(8)}$ We agree that more data could have been reported in that paper. Student's $t$-test comparing mean scores from a Japanese study ${ }^{(9)}$ with those reported in Singapore students showed that Singapore students had a significantly higher mean JSPE-S score (112.18 vs. 104.30, $\mathrm{p}<0.001)$. Similarly, a significant difference in mean scores between a cohort of US students ${ }^{(10)}$ and Singapore students was also observed (114.3 vs. 112.18, $\mathrm{p}<0.001)$. A more extensive review and comparison is beyond the scope of this reply.

As noted in our article, participants' personal information was anonymised and not made known to the researchers and residency staff. Participants were assured of this at various points throughout their response - in the email reminder and the introduction to the survey. We contend that factors the author deemed irrelevant to the study objectives were, in fact, useful and we would have liked the chance to present these factors in our original article; for instance, a significant difference in empathy scores was observed between consumers and non-consumers of alcohol $(p=0.046)$. Such findings might help us to identify those at risk of empathy decline. There were no significant exclusion criteria. Finally, we can confirm that none of the authors participated in the survey as a respondent.

Yours sincerely,

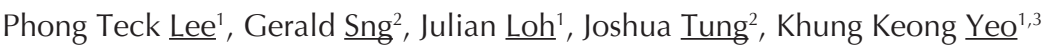

${ }^{1}$ Department of Cardiology, National Heart Centre Singapore, ${ }^{2}$ NUS Yong Loo Lin School of Medicine, National University of Singapore, ${ }^{3}$ Duke-NUS Medical School, Singapore. lee.phong.teck@singhealth.com.sg

\section{References}

1. Ong J, Swift C. Comment on: Empathy and burnout: a study on residents from a Singapore institution. Singapore Med I 2018; 59:166-7.

2. Maslach C, Jackson SE, Leiter MP. The Maslach Burnout Inventory, 1996. Available at: https://www.researchgate.net/profile/Christina_Maslach/publication/277816643_ The_Maslach_Burnout_Inventory_Manual/links/5574dbd708aeb6d8c01946d7.pdf. Accessed February 22, 2017.

3. Grunfeld E, Whelan TJ, Zitzelsberger L, et al. Cancer care workers in Ontario: prevalence of burnout, job stress and job satisfaction. CMAJ 2000; 163:166-9.

4. Sharma A, Sharp DM, Walker LG, Monson JR. Stress and burnout in colorectal and vascular surgical consultants working in the UK National Health Service. Psychooncology. 2008; 17:570-6.

5. Lee PT, Loh J, Sng G, Tung J, Yeo KK. Oct 12. Empathy and burnout: a study on residents from a Singapore institution. Singapore Med J 2018; 59: 50-4.

6. See KC, Lim TK, Kua EH, et al. Stress and burnout among physicians: prevalence and risk factors in a Singaporean internal medicine programme. Ann Acad Med Singapore 2016; 45:471-4.

7. Thomas Jefferson University. Jefferson Scale of Empathy. Available at: http://www.jefferson.edu/university/skmc/research/research-medical-education/jefferson-scaleof-empathy.html. Accessed February 23, 2018.

8. Sng G, Tung J, Ping YS, et al. Complex and novel determinants of empathy change in medical students. Korean J Med Educ 2016; 28:67-78.

9. Kataoka HU, Koide N, Ochi K, Hojat M, Gonnella JS. Measurement of empathy among Japanese medical students: psychometrics and score differences by gender and level of medical education. Acad Med 2009; 84:1192-7.

10. Hojat M, Gonnella JS. Eleven years of data on the Jefferson Scale of Empathy-Medical Student Version (JSE-S): proxy norm data and tentative cutoff scores. Med Princ Pract 2015; 24:344-50. 